\title{
Birds as seed dispersers in deserts: suggestions from the ground-jays
}

\author{
Tiziano Londei* (1)
}

\begin{abstract}
The study of seed dispersal, biotic seed dispersal, and even less, the role of birds in it, have been almost neglected in deserts. Virtually absent from the literature on seed dispersal are the ground-jays, genus Podoces, four species of the crow family that inhabit arid environments, even true deserts, from Iran to Mongolia. Although they are omnivorous, they seem to mainly depend on the seeds of desert plants during the cold season. There are suggestions in sparse literature that they may contribute to seed dispersal similarly to several corvid species of other climates, by caching seeds in useful microsites to save them for later consumption and thus actually favoring the germination of the seeds they fail to recover. Future research might benefit from comparison with the vast literature on their better-known seed-caching relatives. This paper is aimed at providing basic information on each ground-jay species and some suggestions for investigating their likely symbiosis with desert plants, with possible applications to the maintenance and restoration of vegetation in a very extended arid zone.
\end{abstract}

Keywords: Central Asia, Desert birds, Podoces ground-jays, Seed dispersal, Synzoochory

\section{Correspondence}

Deserts have received less attention than other climates for seed dispersal for at least two reasons easily found in literature (e.g. Ellner and Shmida 1981): (1) since desert plants tend to delay germination until the occurrence of rare precipitation events, their survival has more often been understood as dependent on dormancy than on dispersal; (2) assumed lack of devices for long-range dispersal, or presence of traits that hinder dispersal, in their seeds has been explained with the rarity of microsites enhancing seedling establishment. However, these reasons lose value if one considers that: (1) dormancy and dispersal are not necessarily in conflict with each other, as plants of extreme desert environments produce longliving seed banks with deep dormancy as well as having their seeds dispersed by wind in active sand dunes over considerable distances (e.g. Calligonum mongolicum in Fan et al. 2018); (2) animals might search for

*Correspondence: londeit@tin.it Milan, Italy useful microsites to save seeds for later consumption. Such sites might also be suitable for seedling establishment and the animal might fail to recover all the cached seeds, thus favoring the dispersal of the plant. The latter mode of seed dispersal, called synzoochory, is a wellknown occurrence in temperate and tropical climates, but not as well in deserts. In their recent global review on synzoochory based on 2223 case studies, Gómez et al. (2019) included the deserts in a broader Arid category, for which they remarked on the prevalence of rodents and listed (see Appendix S1 in Gómez et al. 2019) only six species of birds among the dispersers. Five of those birds belong in the crow family: Aphelocoma californica, Cyanocitta stelleri, Gymnorhinus cyanocephalus and Nucifraga columbiana from northern America and Garrulus glandarius from Europe. These corvids mainly disperse pines and oaks and are clearly not true desert birds. The same goes for the one non-corvid bird, the American Acorn Woodpecker (Melanerpes formicivorus). In the same paper, a lack of information on synzoochory from large parts of the world was admitted and no study case from Central Asia was included in the Arid category.

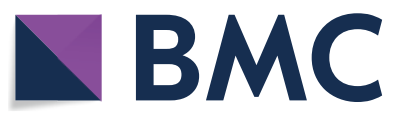

c) The Author(s) 2021. This article is licensed under a Creative Commons Attribution 4.0 International License, which permits use, sharing, adaptation, distribution and reproduction in any medium or format, as long as you give appropriate credit to the original author(s) and the source, provide a link to the Creative Commons licence, and indicate if changes were made. The images or other third party material in this article are included in the article's Creative Commons licence, unless indicated otherwise in a credit line to the material. If material is not included in the article's Creative Commons licence and your intended use is not permitted by statutory regulation or exceeds the permitted use, you will need to obtain permission directly from the copyright holder. To view a copy of this licence, visit http://creativeco mmons.org/licenses/by/4.0/. The Creative Commons Public Domain Dedication waiver (http://creativecommons.org/publicdomain/ zero/1.0/) applies to the data made available in this article, unless otherwise stated in a credit line to the data. 
In fact, considerable attention has been paid to animalplant interaction in arid northwestern China, but only ants were reported as seed-dispersing animals (Liu et al. 2014), while Rhombomys opimus, a widespread Central Asian rodent and conceivably a seed-disperser, suggested different relationships with desert plants (Xu et al. 2015).

Desert birds have mainly been studied as frugivores, classical endozoochorous animals which disperse seeds through gut passage of fleshy fruits (van Rheede van Oudtshorn and van Rooyen 1999; Bronstein et al. 2007). The occurrence of frugivores in arid environments is limited by the rarity of fleshy-fruited plants in the lack of water, and consequently, birds have not been considered as important seed dispersers in deserts. Some corvids are well-known avian counterparts of the scatterhoarding rodents in the temperate zone of the northern hemisphere. Pesendorfer et al. (2016) highlighted their unique aspects as seed dispersers: compared to rodents, corvids are more selective on the quality of the seeds to be cached, disperse them over longer distances, and are not as hesitant to cross unfavorable spaces in fragmented habitats, thus reducing post-dispersal predation (pilferage) from the rodents. De Kort and Clayton (2006) lists 43 corvid species from moderate to specialized food cachers, plus only two non-cachers: the specialized cachers are all inhabitants of well wooded areas, while the moderate cachers use more diverse habitats. The inclusion of a desert species, a ground-jay, in the moderate cachers is based on Bardin (2006), though the behavioural description by Bardin would rather suggest the specialized cacher, as reported in the following content for evidence for ground-jays as seed dispersers in deserts. Unfortunately, no equally informative description exists either for this or other ground-jay species as food cachers.

There is sparse, though growing, information on the general habits of these unusual corvids of Central Asian deserts, more prone to move around on foot than in flight, hence the generic name Podoces, in no larger associations than family groups. Madge (2009) gives the most comprehensive overview of the four species. Among their shared traits, especially pertinent to the present topic is that they live in arid environments with strong seasonality and consequently they change from mainly animal to mainly vegetal diets in the cold season. No quantitative study exists of their relationship with seed dispersal. The Turkestan Ground-jay (Podoces panderi) is probably the best studied species. Kovshar (2015) reports Bardin's (2006) description of birds collecting and burying Haloxylon seeds in the Karakum Desert, in October. Several points in that detailed description suggest the specialized seed-disperser. Weighing "about $5 \mathrm{mg}$ each" (see also Liu et al. 2014), Haloxylon seeds would be the smallest seeds dispersed by seed-storing corvids (compare with mass values of Table 7.2 in Tomback 2016). The "hyoid bag" where the Turkestan Ground-jays placed "several hundred seeds" reminds of the sublingual pouch of the Nucifraga nutcrackers, an adaptation of some of the bestknown seed-dispersers to carry seeds efficiently over potentially extensive distances (Bock et al. 1973). The caching technique, through which the stocks were hidden by covering the holes with well-leveled sand, or pieces of other surrounding material, reveals the adaptation to avoiding that caches are stolen by other animals, including conspecifics. This is a well-known corvid behaviour (see e.g. description and fine photographs in Kurek et al. 2018 concerning Garrulus glandarius). The moderate burial depth, $2.5-4 \mathrm{~cm}$, was close to the optimum for germination and seedling emergence in a plant of similar habitat (Fan et al. 2018). The Russian common name for the Turkestan Ground-jay, saksaul'naya soika (Saxaul Jay), mirrors its habitat, a sandy desert with saxaul shrub, Haloxylon aphyllum or Haloxylon persicum, dominant. As neither Haloxylon species produces seeds every year (Rustamov 1994), it may be interesting to know whether the birds move among saxaul grows that fruit in different years, or they can alternatively rely on other plants for seed provision. Kovshar (2015) reported the presence of the seeds of other desert plants in stomach contents, although with no suggestion that they were from caches. Zhatkanbayev (2015) observed Turkestan Ground-jays in the snow while plucking the remaining fruits from emergent clumps not only of Haloxylon but also of Stipagrostis and other "low-growing desert plants", in addition to apparently searching for previous caches.

The Iranian Ground-jay (Podoces pleskei) is a sister species of the Turkestan Ground-jay and lives in less arid areas, where it nests on a variety of shrubs and bushes (e.g. Nazarizadeh et al. 2015). Although its biology is increasingly studied, little is known about its possible relationship with seed dispersal. Hamedanian (1997) stated that "this species holds some extra food in its throat sac before burying it in holes in the ground", and claimed that, "as hiding food is a habit of members of the family and Pleske's Ground Jay feeds almost entirely on plant seeds in the autumn, so the bird can play an important role in planting different scrubs and borage plants of its desert habitat". Radnezhad et al. (2011) found seeds of Zygophyllum eurypterum in the fecal sacs of nestlings, arguably no later than in May, the later time of fledging found in the study areas. As the seeds of this shrub apparently begin to mature at the end of June in Iran (Ghasemi et al. 2017), it seems likely that the ingested seeds were from caches of the previous year. The Mongolian Ground-jay (Podoces hendersoni) is adapted to the coldest deserts of Central Asia and prefers gravel 
surface, even with very scarce vegetation. Kurochkin and Mikhailov (1994) observed birds burying almond nuts in cracks of the soil, and Ilyashenko et al. (2017) reported chicks being fed in April with Amygdalus mongolica kernels taken by the parents from under stones. Considering that this plant fruits in August-September (http://www. efloras.org), this observation seems to be the best available evidence for any ground-jay species that autumn caches are used as spring food. It may be worth noting for future research that Mongolian Ground-jays were found widespread in the Junggar Basin, northwestern China (Londei 2000), where wild Amygdalus almonds are absent (http://www.efloras.org) and thus this ground-jay might also rely on caches from other plants. The Xinjiang Ground-jay (Podoces biddulphi) has its distribution surrounded by, but not mixed with, the distribution of the Mongolian Ground-jay, of which it is the closest relative. It is endemic to the Taklimakan Desert and able to live even in the harsh interior of this sandy desert, providing that groundwater is accessible to vegetation in low areas between the dunes (Ma and Kwok 2004; Ma 2011). The artificial irrigated vegetal belt that protects the Taklimakan Desert Highway from encroaching sand has been found to positively affect the occurrence of Xinjiang Ground-jays along the road, a phenomenon ascribed to these plants providing cover, drinking water, food, and nesting sites (Londei 2011; Xu et al. 2013). These birds were found to have seeds in their diet and were also observed, in the end of summer, collecting food left by humans along the road and quickly burying it in the sand, rather than eating it (Ma 2004). It may be worth investigating whether the vegetal belt itself benefits from the presence of the birds, in terms of better survival of buried seeds.

Future study of the ground jays will likely take advantage of comparison with the vast literature on those corvids that are well-known seed-dispersers in temperate climates. The references in de Kort and Clayton (2006) are a useful source of anatomical and eco-ethological studies, as well as experimental tests, of foodcaching behaviour in corvids. Ground-jays suggest a seemingly unexplored connection of this behaviour with the omnivorous strategy of all corvids: Turkestan Ground-jays were observed, in winter, finding the egg capsules of the Desert Locust (Caliptamus barbarus) under snow-covered soil (Zhatkanbayev and Zhatkanbayeva 2017) and it seems therefore possible that their ability in observational learning, necessary to recover their own caches and also useful to steal the others', makes them also especially fit for detecting hidden animal prey. If so, the ground-jays might be of further advantage to desert vegetation, by performing pest control during critical stages of the life of the pest. The desert plants mentioned in the present paper as candidates for having their seeds dispersed by ground-jays seem all important for environmental maintenance and restoration. Calligonum and Haloxylon genera, which were both found as seeds in the stomachs of Turkestan Ground-jays (Rustamov 1954; Kovshar 2015), were found in China to be important tools in desert afforestation (Zhang et al. 2016). Zygophyllum eurypterum has been studied among important rangeland plants with dormant seeds that rarely germinate in "usual natural conditions" (Sharififar et al. 2015) - it might be worth investigating whether ground-jays provide the seeds with more favorable natural conditions than those usually considered. Amygdalus mongolica, a shrub of gravel semidesert that survives in refugia unaffected by overgrazing, seems to be a promising candidate for rangeland restoration (Chu et al. 2015). The ground-jays may be more common than expected for so scarcely studied birds. Although concern for degradation of their habitats appears in literature (see Burnside et al. 2020 for a recent account), one should consider that, as usual in corvids, ground-jays have benefited from some manmodified environment, see the Taklimakan Desert Highway. Such adaptability might make their ecosystem services especially useful in transitional situations towards environmental restoration. Compared to winds and seasonal floods, the usual abiotic agents of seed dispersal in deserts, the ground-jays would choose where leave the seeds for keeping them viable in their own interest of future consumers, and the plants might have obtained better germination in such environments from a co-evolution with the ground-jays resulting in mutualistic symbiosis. Given their geographical distribution and the recurrent mention in literature of "other plants" in addition to those specified in their diets, the ground-jays might serve as seed dispersers for a variety of plants throughout the most extended continuum of arid and semi-arid land on Earth.

\author{
Acknowledgements \\ full appraisal of the topic. \\ Funding \\ Not applicable. \\ Availability of data and materials \\ Not applicable.

\section{Declarations} \\ Ethics approval and consent to participate \\ Not applicable. \\ Consent for publication \\ Not applicable.
}

Ruben H. Heleno and Valentin Yu. Ilyashenko suggested important papers for 


\section{Competing interests}

The author declare that he has no competing interests.

Received: 27 January 2021 Accepted: 16 March 2021

Published online: 03 April 2021

\section{References}

Bardin AV. Behaviour of the saxaul jay Podoces panderi when storing food. Ruskiy Ornitologicheskiy Zhurnal. 2006;307:54-6 (in Russian)

Bock WJ, Balda RP, Vander Wall SB. Morphology of the sublingual pouch and tongue musculature in Clark's nutcracker. Auk. 1973;90:491-519.

Bronstein JL, Izhaki I, Nathan R, Tewksbury JJ, Spiegel O, Lotan A, et al. Fleshyfruited plants and frugivores in desert ecosystems. In: Dennis AJ, Schupp EW, Green RJ, Westcott DA, et al. editors. Seed dispersal: theory and its application in a changing world. Wallingford: CAB International; 2007. p. 148-77.

Burnside RJ, Brighten AL, Collar NJ, Soldatov V, Koshkin M, Dolman PM, et al. Breeding productivity, nest-site selection and conservation needs of the endemic Turkestan Ground-jay Podoces panderi. J Ornithol. 2020;161:1175-83.

Chu J, Yang H, Lu Q, Zhang X. Endemic shrubs in temperate arid and semiarid regions of northern China and their potentials for rangeland restoration. AoB Plants. 2015;7:plv063.

de Kort SR, Clayton NS. An evolutionary perspective on caching by corvids. Proc R Soc Biol Sci. 2006;273:417-23.

Ellner S, Shmida A. Why are adaptations for long range seed dispersal rare in desert plants? Oecologia. 1981;51:133-44.

Fan B, Zhou Y, Ma Q, Yu Q, Zhao C, Sun K. The bet-hedging strategies for seedling emergence of Calligonum mongolicum to adapt to the extreme desert environments in northwestern China. Front Plant Sci. 2018;9:1167.

Ghasemi AG, Maybodi NB, Zarei G, Alishah F. The effects of seed harvesting time on viability of Salsola rigida Pall, Zygophyllum eurypterum Boiss \& Buhse and Ferula ovina (Boiss) Boiss in Yazd province watershed. Manage Res. 2017;29:2-8.

Gómez JM, Schupp EW, Jordano P. Synzoochory: the ecological and evolutionary relevance of a dual interaction. Biol Rev. 2019;94:874-902.

Hamedanian A. Observations of Pleske's Ground Jay Podoces pleskei in central Iran. Sandgrouse. 1997;19:88-91.

llyashenko V, llyashenko E, Gungaa A, Purev-Ochir G. On the biology of the Mongolian Ground Jay Eupodoces hendersoni Hume, 1871. Selevinia. 2017;25:7-15 (in Russian with English summary).

Kovshar AF. Pander's Ground-jay (Podoces panderi J. G. Fisher, 1821) - endemic species of Middle Asian deserts. Selevinia. 2015;23:9-32 (in Russian with English summary)

Kurek P, Dobrowolska D, Wiatrowska B. Dispersal distance and burial mode of acorns in Eurasian Jays Garrulus glandarius in European temperate forests. Acta Ornithol. 2018;53:155-62.

Kurochkin EN, Mikhailov KE. Nesting avifauna of the Gobi territory of Mongolia. In: Sovremennaya ornitologiya 1992. Moscow: Nauka; 1994. p. 50-75 (in Russian)

Liu H, Zhang D, Duan S, Wang X, Song M. The relationship between diaspore characteristics with phylogeny, life history traits, and their ecological adaptation of 150 species from the cold desert of Northwest China. Sci World J. 2014;2014:510343.

Londei T. Observations on Henderson's Ground Jay Podoces hendersoni in Xinjiang China. Bull BOC. 2000;120:209-12.
Londei T. Podoces ground-jays and roads: observations from the Taklimakan Desert China. Forktail. 2011;27:109-11.

Ma M. Xinjiang Ground Jay Podoces biddulphi: an endemic species in Taklimakan Desert. Urumqi: Xinjiang Science and Technology Publishing House; 2004 (in Chinese with English preface and content).

Ma M. Status of the Xinjiang Ground Jay: population, breeding ecology and conservation. Chinese Birds. 2011;2:59-62.

Ma M, Kwok HK. Records of Xinjiang Ground-jay Podoces biddulphi in Taklimakan Desert, Xinjiang. China Forktail. 2004;20:121-4.

Madge SC. Podoces species accounts. In: del Hoyo J, Elliott A, Christie DA, editors. Handbook of the birds of the world 14. Barcelona: Lynx; 2009. p. 609-11.

Nazarizadeh M, Fatemizadeh F, Kaboli M, Cheraghi S, Hashemi A, Tohidifar M. Home range of Pleske's Ground Jay Podoces pleskei in a breeding season in Touran Biosphere Reserve, north-central Iran. Podoces. 2015;10:8-14.

Pesendorfer MB, Sillett TS, Koenig WD, Morrison SA. Scatter-hoarding corvids as seed dispersers for oaks and pines: a review of a widely distributed mutualism and its utility to habitat restoration. Condor. 2016;1 18:215-37.

Radnezhad H, Satei N, Kaboli M, Karami M, Khorasani N, Prodon R, et al. Breeding ecology of the Iranian ground jay (Podoces pleskei). Afr J Biotechnol. 2011;10:4494-500.

Rustamov AK. Birds of the Karakum Desert. Ashgabat: Proceedings of the Turkmen Academy of Sciences TSSR; 1954 (in Russian).

Rustamov IG. Vegetation of the deserts of Turkmenistan. In: Fet V, Atamuradov Kl, editors. Biogeography and ecology of Turkmenistan. Dordrecht: Springer; 1994. p. 77-104.

Shariffiar A, Nazari M, Asghari HR. Effect of ultrasonic waves on seed germination of Atriplex lentiformis, Cuminum cyminum, and Zygophyllum eurypterum. JARMAP. 2015;2:102-4.

Tomback DF. Seed dispersal by corvids: birds that build forests. In: Şekercioğlu $\mathrm{CH}$, Wenny DG, Whelan CJ, editors. Why birds matter: avian ecological function and ecosystem services. Chicago: University of Chicago Press; 2016. p. 196-234.

van Rheede van Oudtshorn K, van Rooyen MW. Dispersal biology of desert plants. Berlin: Springer; 1999.

Xu W, Liu W, Yang W, Wang M, Xu F, Blank D. Impact of great gerbils (Rhombomys opimus) on desert plant communities. J Arid Land. 2015;7:852-9.

Xu F, Yang W, Xu W, Xia C, Liao H, Blank D. The effects of the Taklimakan Desert Highway on endemic birds Podoces biddulphi. Transp Res D-Tr E. 2013;20:12-4

Zhang JG, Lei JQ, Wang YD, Zhao Y, Xu XW. Survival and growth of three afforestation species under high saline drip irrigation in the Taklimakan Desert China. Ecosphere. 2016;7:e01285.

Zhatkanbayev AZ. Extraordinary, unusual early beginning of reproductive cycle by Turkestan Ground-jay of Ile subspecies (Podoces panderi ilensis) in Southern Balqash desert valley - adaptive response of only one endemic bird creature among whole Qazaqstan avifauna onto chancing weather-climatic conditions (Part I, II, III). News of the National Academy of Science of the Republik of Kazakhstan, Series of Biological and Medical. 2015;1:10-33; 2:25-47 and 4:26-40 (in Russian with English summary).

Zhatkanbayev AZh, Zhatkanbayeva DM. Insects in the diet of Turkestan Ground-jay Podoces panderi ilensis Menzb. et Schnitn. in the southern Balqash Desert region, south-east Kazakhstan. Izvestiya Samarskogo nauchnogo tsentra Rossiyskoy akademii nauk. 1915;2017(19):65-72 (in Russian with English summary). 